\title{
Posterior sternoclavicular joint dislocation: case report and discussion
}

\author{
Nick Kuzak, BSc, MD; ${ }^{* \dagger}$ Adrian Ishkanian, MSc; ${ }^{\ddagger}$ Riyad B. Abu-Laban, MD, MHSc ${ }^{* \S}$
}

\begin{abstract}
The sternoclavicular joint is the most frequently mobilized non-axial, major joint, but is the least frequently dislocated. Most sternoclavicular dislocations are anterior. When posterior sternoclavicular joint dislocations do occur, they may present with a variety of signs and symptoms, including serious intrathoracic injuries. We discuss the case of a patient with a subacute posterior sternoclavicular dislocation who presented to the emergency department 2 months after being hit in the posterior neck. We also review the signs, symptoms and management of posterior sternoclavicular dislocation and the literature on this topic.
\end{abstract}

Key words: sternoclavicular, dislocation

\begin{abstract}
RÉSUMÉ
L'articulation sterno-claviculaire est l'articulation non axiale importante la plus souvent mobilisée, mais c'est celle qui subit le moins souvent de luxations. La plupart des luxations sterno-claviculaires sont antérieures. Lorsque des luxations postérieures se produisent, elles peuvent être accompagnées d'une variété de signes et symptômes, incluant des blessures intrathoraciques graves. Nous discutons du cas d'un patient victime d'une luxation sterno-claviculaire postérieure subaiguë deux mois après qu'il eut été frappé à la partie postérieure du cou. Nous examinons également la littérature à ce sujet.
\end{abstract}

\section{Case report}

A 37-year-old woman presented to the emergency department (ED) 2 months after being hit by a boom in the posterior neck and shoulder while sailing. She complained of retrosternal chest pain and difficulty swallowing, both of which were exacerbated by arm movement and recumbancy. Her pain had initially been severe, but it had subsided over 3 days. She had no shortness of breath, pleuritic chest pain, cough, hemoptysis, dsyphonia, odynophagia or neurologic symptoms. Her past medical history was unremarkable. She had sought medical advice for this injury on 2 previous occasions and had been advised to rest and take nonsteroidal, anti-inflammatory medications.
On examination, the patient was seated and appeared comfortable. Her temperature was $36.3^{\circ} \mathrm{C}$, pulse 56 beats/min, respiratory rate 16 breaths/min, blood pressure $124 / 73 \mathrm{~mm} \mathrm{Hg}$, and oxygen saturation by pulse oximetry $99 \%$. There was no swelling, ecchymosis or erythema of the neck, chest or extremities. The airway, respiratory and cardiovascular systems were unremarkable. There was no subcutaneous emphysema. Musculoskeletal examination revealed tenderness of the medial left clavicle, and less prominence of the left clavicle than the right. The left clavicular head could not be palpated. Pressure on the medial left clavicle reproduced the patient's chest pain and dysphagia. Neurologic and vascular examination of the upper extremities was unremarkable.

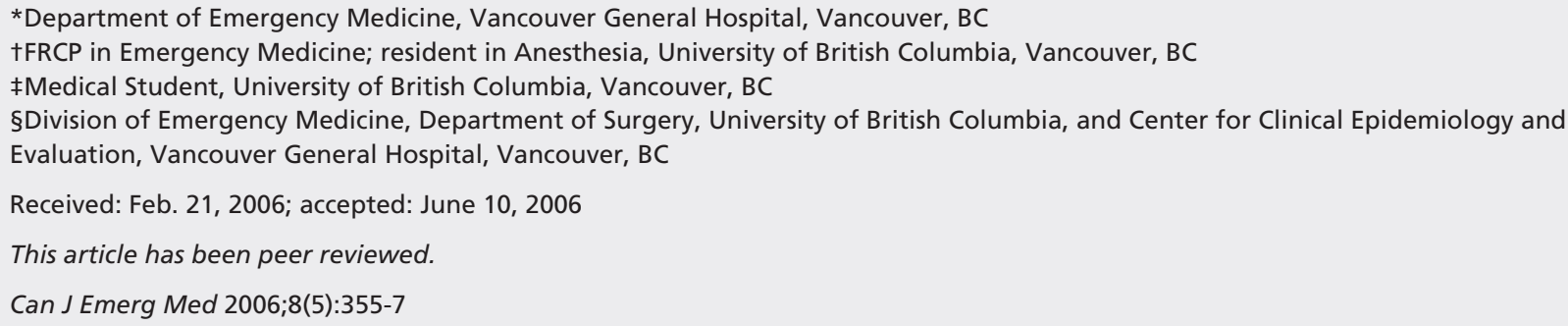


Plain radiography showed displacement of the left clavicle (Fig. 1). A non-contrast CT scan of the chest and mediastinum demonstrated a left posterior sternoclavicular joint (SCJ) dislocation with bony fragments in the left anteroinferior aspect of the medial third of the left clavicle (Fig. 2). The displaced medial clavicle was in contact with the superior and anterior aspect of the left brachiocephalic vein, and the clavicular head abutted the proximal left common carotid and brachiocephalic arteries. No abnormalities of the trachea, esophagus or lungs were identified. An injury to the left brachiocephalic vein, artery or common carotid artery could not be excluded radiographically.

The patient was seen by orthopedics while in the ED, fitted with a sling and discharged home after arrangements were made for a reduction under general anesthesia. Open reduction proceeded uneventfully 1 week later.

\section{Discussion}

\section{Background}

While the SCJ is the most frequently mobilized, non-axial joint, it is the least frequently dislocated one. This is due to stability provided by the sternoclavicular, interclavicular and costoclavicular ligaments. ${ }^{1,2}$ Although sprains of the SCJ are common, dislocations are rare because they require a complete rupture of the costoclavicular ligament. SCJ dislocations make up 3\% of all shoulder girdle injuries. ${ }^{3}$ Approximately 120 published cases of posterior SCJ dislocation have been described previously, with only 4 presenting (as our patient did) in a subacute fashion. ${ }^{4}$ The ratio of anterior to posterior dislocations is approximately 9 to $1 .{ }^{1,45}$ The classification of SCJ instability is based on the degree, timing, direction and cause of the subluxation or dislocation. ${ }^{1}$ Chronic SCJ dislocations are extremely rare, and a MEDLINE review from 1966 to 2005 found only 4 reported cases..$^{6-8}$

Motor vehicle crashes and sports injuries are the most common causes of SCJ dislocation. In most cases the mechanism is a compressive force applied to the posterolateral aspect of the shoulder. Another potential mechanism is from direct impact to the anteromedial clavicle. ${ }^{1,2}$ Blunt

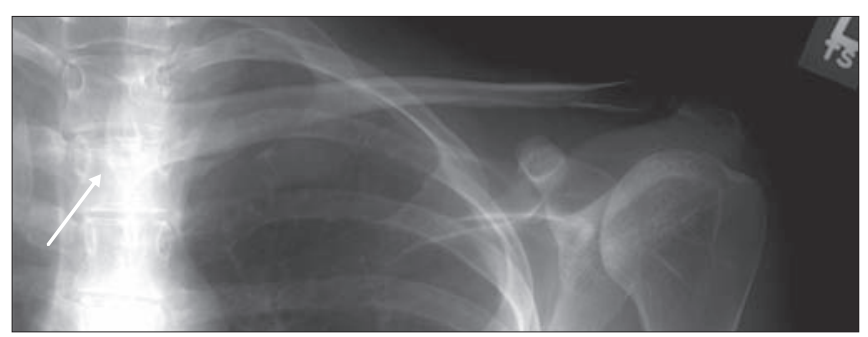

Fig. 1. Anterior-posterior radiograph of left clavicle. Arrow indicates displacement. trauma to the posterior neck and shoulder, as our patient experienced, has not been previously described as a mechanism for posterior SCJ dislocation.

\section{Physical findings}

Acute posterior SCJ dislocations usually present with pain and swelling in the area of the SCJ. Most upper limb movements transfer force to the SCJ, so that pain is often exacerbated by arm movement, lateral shoulder compression, coughing, sneezing or deep breathing. The shoulder on the affected side may appear to be rolled anteriorly. Patients often subconsciously attempt to relieve pressure on the SCJ by lateral neck flexion toward the affected side. Presenting symptoms can include dsyphonia, dysphagia, dyspnea and occasionally paresthesias or reduced sensation in the upper extremity. ${ }^{1,2}$

Posterior SCJ dislocations are frequently missed in the setting of major trauma due to the subtlety of the clinical findings. Inspection may reveal the medial aspect of the clavicle to be receded relative to the lateral aspect. Clavicular asymmetry may be better appreciated when viewed from above the patient's head. Although palpation of the clavicular notch may be possible, tenderness and swelling around the SCJ often masks the posterior displacement, thus making it difficult to clinically distinguish dislocations from sprains and subluxations. ${ }^{1,2}$

Posterior SCJ dislocation may be associated with potentially life-threatening emergencies due to the proximity of vital superior mediastinal structures. Posterior dislocations have associated intrathoracic or superior mediastinal injuries in up to $30 \%$ of cases. The mortality in this subset of patients is reported to be $12.5 \%$, and such associated conditions must be ruled out before attempting reduction. Injuries associated with posterior SCJ dislocation include compression or laceration of the great vessels, tracheal compression or rupture, esophageal compression or rupture, injury to the brachial plexus and pleural disruption, which may lead to pneumothorax or subcutaneous emphysema. ${ }^{1,2,9}$

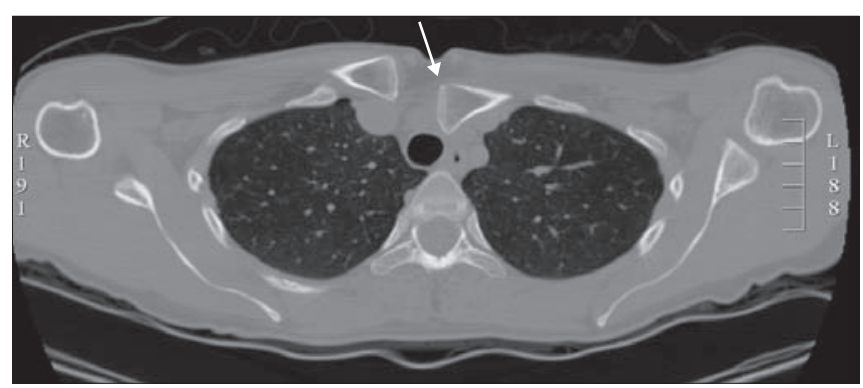

Fig. 2. Non-contrast CT of the chest. Arrow indicates posterior dislocation of left medial clavicle with encroachment on the trachea. 


\section{Diagnostic imaging}

Plain radiography and $\mathrm{CT}$ are the primary imaging modalities for potential SCJ pathology. Standard radiographic views may not provide a definitive diagnosis. A "serendipity" view, where the $\mathrm{x}$-ray beam is angled $40^{\circ}$ cephalad to the anterior-posterior axis, may be helpful. ${ }^{5}$ Although this view may allow an accurate determination of the direction of dislocation, it will not identify any associated mediastinal injuries. CT with contrast is the primary modality for definitive evaluation of acute SCJ dislocation. Occasionally, arteriography and/or venography is required to further evaluate the great vessels. ${ }^{5}$

\section{Management}

Management of SCJ pathology is dependent on the degree of injury. A sprain of the sternoclavicular or costoclavicular ligament should be considered when there is no joint instability on clinical exam and the patient has only mild to moderate pain. Analgesia, ice, and shoulder immobilization with a sling usually leads to complete recovery in 7 to 10 days. Subluxation of the SCJ with an intact costoclavicular joint is treated with a sling or the application of a clavicular splint for 3 to 6 weeks. ${ }^{1}$

Management options for posterior SCJ dislocations include closed reduction in the $\mathrm{ED}$, using procedural sedation, or orthopedic reduction in the operating room under general anesthesia. Immediate ED reduction should be performed in cases involving airway compression or major vascular compromise. The classically described approach for reduction involves placing the patient supine with a rolled towel between the scapulae. After appropriate procedural sedation, traction is applied to the abducted arm while it is gradually extended. If reduction cannot be achieved, a towel clip can be used to grasp the clavicle and provide additional anterior traction.

Buckerfield and Castle described an alternative closed reduction technique in 1984. The ipsilateral arm is adducted against the torso and caudal traction is applied. Simultaneously, both shoulders are pushed posteriorly by an assistant. This manoeuvre levers the medial clavicles superiorly over the first rib and maneubrium. This technique was reported to be successful in 3 posterior SCJ dislocations that had previously failed closed reduction using the classic approach. ${ }^{10}$ Following reduction, immobilization in a figure of 8 splint and sling for $6-8$ weeks is indicated. The reported success rate for closed reduction using the classic abduction and extension technique is approximately $80 \% .^{1,2,10,11}$

Open reduction is indicated if closed reduction fails or if the SCJ is chronically unstable. ${ }^{9,11}$ Transarticular fixation is no longer used to repair chronic SCJ dislocations since the complex rotational and translational forces on this joint can cause fixation pins to become dislodged, potentially compromising mediastinal structures..$^{12}$ Most open reductions are stable, and require similar postoperative care to closed reductions. ${ }^{5}$

\section{Conclusions}

The SCJ is infrequently dislocated, with most of these dislocations anterior. Posterior SCJ dislocation can occur, however, and may present with a variety of signs and symptoms. Posterior SCJ dislocation has the potential to include serious or life threatening associated intrathoracic injuries. Although clinical exam may raise suspicion for this injury, CT is required for definitive diagnosis and for assessment of associated injuries. Closed reduction is the treatment of choice, and is successful in approximately $80 \%$ of cases. Open reduction is required if closed reduction fails or if the SCJ is chronically unstable.

Competing interests: None declared.

Acknowledgement: Dr. Riyad B. Abu-Laban is supported by a Clinical Scholar Award from the Michael Smith Foundation for Health Research.

\section{References}

1. Yeh GL, Williams GR. Conservative management of sternoclavicular injuries. Orthop Clin North Am 2000;31:189-203.

2. Bulstrode CKJ, et al, editors. Oxford textbook of orthopedics and trauma. 10th ed. Oxford: Oxford University Press; 2001. p. 693-6; 2053-5.

3. Cave ER, Burke JF, Boyd RJ. Trauma management. Chicago: Year Book Medical; 1974. p. 409-11.

4. Nettles JL, Linscheid RL. Sternoclavicular dislocations. J Trauma 1968;8(2):158-64.

5. Rockwood CA, Wirth MA. Fractures in adults. 5th ed. Philadelphia: Lippincott-Raven; 2001. p. 1245-92.

6. Jain S, Monbaliu D, Thompson JF. Thoracic outlet syndrome caused by chronic retrosternal dislocation of the clavicle. Successful treatment by transaxillary resection of the first rib. J Bone Joint Surg Br 2002;84:116-8.

7. Noda M, Shiraishi H, Mizuno K. Chronic posterior sternoclavicular dislocation causing compression of a subclavian artery. J Shoulder Elbow Surg 1997;6:564-9.

8. Rayan GM. Compression brachial plexopathy caused by chronic posterior dislocation of the sternoclavicular joint. J Okla State Med Assoc 1994;87:7-9.

9. Wirth MA, Rockwood CA Jr. Acute and chronic traumatic injuries of the sternoclavicular joint. J Am Acad Orthop Surg 1996;4:268-78.

10. Buckerfield CT, Castle ME. Acute traumatic retrosternal dislocation of the clavicle. J Bone Joint Surg Am 1984;66:379-85.

11. Canale ST, editor. Campbell's operative orthopaedics. 10th ed. Elsevier Canada; 2003. p. 2395-6; 3177; 3196-7.

12. Venissac N, Alifano M, Dahan M, et al. Intrathoracic migration of Kirschner pins. Ann Thorac Surg. 2000;69(6):1953-5.

Correspondence to: Dr. Nick Kuzak, Department of Emergency Medicine, Vancouver General Hospital, 855 West 12th Ave., Vancouver BC V5Z 1M9 